\title{
Atmospheric forcing of Fram Strait sea ice export: a closer look
}

\author{
Maria Tsukernik · Clara Deser · Michael Alexander • \\ Robert Tomas
}

Received: 20 March 2009/ Accepted: 6 August 2009/Published online: 26 August 2009

(C) Springer-Verlag 2009

\begin{abstract}
Fram Strait is the primary region of sea ice export from the Arctic and therefore plays an important role in regulating the amount of sea ice and freshwater within the Arctic. We investigate the variability of Fram Strait sea ice motion and the role of atmospheric circulation forcing using daily data during the period 1979-2006. The most prominent atmospheric driver of anomalous sea ice motion across Fram Strait is an east-west dipole pattern of Sea Level Pressure (SLP) anomalies with centers of action located over the Barents Sea and Greenland. This pattern, also observed in synoptic studies, is associated with anomalous meridional winds across Fram Strait and is thus physically consistent with forcing changes in sea ice motion. The association between the SLP dipole pattern and Fram Strait ice motion is maximized at 0-lag, persists year-round, and is strongest on time scales of 10-60 days. The SLP dipole pattern is the second empirical orthogonal function (EOF) of daily SLP anomalies in both winter and summer. When the analysis is repeated with monthly data, only the Barents center of the SLP dipole remains significantly correlated with Fram Strait sea ice motion. However, after removing the leading EOF of monthly SLP variability (e.g., the North Atlantic Oscillation), the full east-west dipole pattern is recovered. No significant SLP forcing of Fram Strait ice motion is found in summer using
\end{abstract}

M. Tsukernik $(\varangle) \cdot$ C. Deser $\cdot$ R. Tomas

Climate and Global Dynamics Division, National Center for Atmospheric Research (NCAR), P.O. Box 3000, Boulder, CO 80307, USA

e-mail:masha@ucar.edu

M. Alexander

NOAA Earth System Research Laboratory, Boulder, USA monthly data, even when the leading EOF is removed. Our results highlight the importance of high frequency atmospheric variability in forcing Fram Strait sea ice motion.

Keywords Fram Strait - Sea ice motion - Sea ice export . North Atlantic Oscillation · East-west dipole .

High frequency atmospheric variability

\section{Introduction}

Fram Strait, located between Greenland and Svalbard, is the primary gateway for the export of sea ice out of the Arctic (e.g., Kwok et al. 2004). Fram Strait sea ice export is highly variable from day to day and from year to year (Vinje 2001; Brummer et al. 2001, 2003; Kwok 2009). Such high variability affects other components of the Arctic climate system: for example, anomalous Fram Strait export has been linked to the "Great Salinity Anomaly" in the North Atlantic (Dickson et al. 1988) and to the recent decline of summer sea ice extent (Rigor and Wallace 2004).

The relationship between the large-scale patterns of atmospheric variability especially the North Atlantic Oscillation (NAO; Hurrell 1995) and the related Arctic Oscillation (AO; Thompson and Wallace 1998) with sea ice export through Fram Strait has been investigated in numerous studies, for example: Kwok and Rothrock 1999; Hilmer and Jung 2000; Jung and Hilmer 2001; Vinje 2001; Rigor et al. 2002; Kwok et al. 2004. During the last two decades of the twentieth century (e.g., 1978-1997) the correlation between the NAO and sea ice export through Fram Strait was highly positive (e.g., Hilmer and Jung 2000, Kwok et al. 2004); however, the correlation during other time periods (e.g., 1958-1977) was near zero or even 
slightly negative (Hilmer and Jung 2000; Vinje 2001; Jung and Hilmer 2001).

Given the ambiguity in the relationship between the NAO/AO and Fram Strait sea ice export, Wu et al. (2006) and $\mathrm{Wu}$ and Johnson (2007) investigated whether other patterns of atmospheric variability are related to the ice export in winter. Wu et al. (2006; see also Koenigk et al. 2006) identified an east-west dipole pattern with centers of action over the Kara/Laptev Seas and the Canadian Archipelago to be an important forcing for sea ice export through Fram Strait, while Wu and Johnson (2007) argued that another pattern with a center of action over the Barents Sea plays even a bigger role. Maslanik et al. (2007) indicated that the strength and position of the centers of action of atmospheric circulation variability associated with sea ice motion within the Arctic basin are affected by cyclone frequency and strength, and that both factors vary considerably from year to year.

To examine the link between sea ice export and atmospheric circulation patterns in more detail, Brummer et al. (2003) analyzed how a single cyclone passing through Fram Strait influences sea ice motion. They found that ice velocity increased by a factor of three during the passage of the cyclone, and that the ratio of ice drift to wind speed also increased. Brummer et al. (2001) analyzed 16 years of cyclone statistics from ERA-40 and corresponding sea ice drift observations. They found that sea ice motion is quite sensitive to the particular cyclone trajectory and concluded that, on average, cyclones increase sea ice export through Fram Strait. Rogers et al. (2005) investigated the role of winter cyclones in Fram Strait sea ice export and found a correspondence between increased cyclogenesis along the northeast coast of Greenland and low sea ice export. High sea ice export years, on the other hand, corresponded to the persistent cyclones in the Norwegian and Barents Seas. Using a case study approach, Tsukernik (2007) illustrated how a particular cyclone trajectory influences sea ice motion: a cyclone passing through Fram Strait can completely reverse the direction of sea ice export, while a cyclone passing east of Fram Strait dramatically increases the sea ice export. The relationship between Fram Strait sea ice flux and the SLP gradient across the Strait has been noted in several studies, including Vinje (2001), Widell et al. (2003), and Kwok (2009). In particular, Widell et al. (2003) found that the SLP gradient explained approximately $60 \%$ of the variability in Fram Strait sea ice motion in both daily and monthly averaged data.

Although the topic of atmospheric influence on Fram Strait sea ice export has received a lot of attention, there is still a gap between the monthly averaged studies that relate the sea ice export to large-scale atmospheric patterns and the synoptic-scale studies that investigate the role of high frequency atmospheric disturbances in sea ice export. To bridge this gap, we use daily data to investigate the relationship between the atmospheric circulation and sea ice export over a range of time scales. Due to the scarcity of sea ice thickness measurements, we focus on the areal flux of sea ice through Fram Strait based on satellite estimates of sea ice motion. We investigate the spatial structure and temporal evolution of the SLP patterns associated with variations in sea ice motion through Fram Strait, including its seasonal and frequency dependence. This paper is organized as follows. In Sect. 2 we describe the datasets and methods used in this study. In Sect. 3 we present main results, and in Sect. 4 we summarize our results and discuss them along with findings from previous research.

\section{Data and methods}

We use 6-hourly NCEP/NCAR Reanalysis (Kalnay et al. 1996) SLP and daily sea ice motion vectors from the $25 \mathrm{~km}$ Polar Pathfinder product available from the National Snow and Ice Data Center (Fowler 2003) during 1979-2006. Since we are interested in Fram Strait sea ice export, we derive an index of the meridional component of sea ice motion averaged across the Strait $\left(20^{\circ} \mathrm{W}-15^{\circ} \mathrm{E}, 79^{\circ}-81^{\circ} \mathrm{N}\right.$; region in red outlined in Fig. 1). A negative sea ice index indicates northward ice motion, while a positive sea ice index indicates southward ice motion across Fram Strait. We smooth the 6-hourly NCEP SLP data using a running five-point centered average to produce daily averages that match the resolution of the sea ice index. To define daily anomalies we remove the first two harmonics of the seasonal cycle from both the sea ice index and the gridded SLP time series.

We use linear correlation and regression analysis to define anomalous SLP conditions associated with changes in sea ice export. The statistical significance of the correlation and regression values is assessed using a 2-sided student $t$ test, taking into account the autocorrelation of both series (Press et al. 1986). In order to investigate the relationship between the atmospheric circulation and sea ice export on different timescales we perform cross-spectrum analysis (Bloomfield 1976) and estimate the 99\% significance level following Julian (1975) which takes auto-correlation into account. Based on the cross-spectrum results, we define a band pass filter with half-power points at 10 and 60 days (Duchon 1979).

To investigate the seasonal dependence of the sea iceatmosphere relationship, we divide record into two seasons: winter (15 October-14 April) and summer (15 April14 October). We subsequently apply all of the techniques described above to the two seasons separately. As the cross-spectrum can only be calculated for a continuous time period, we calculate the spectrum for each winter and 

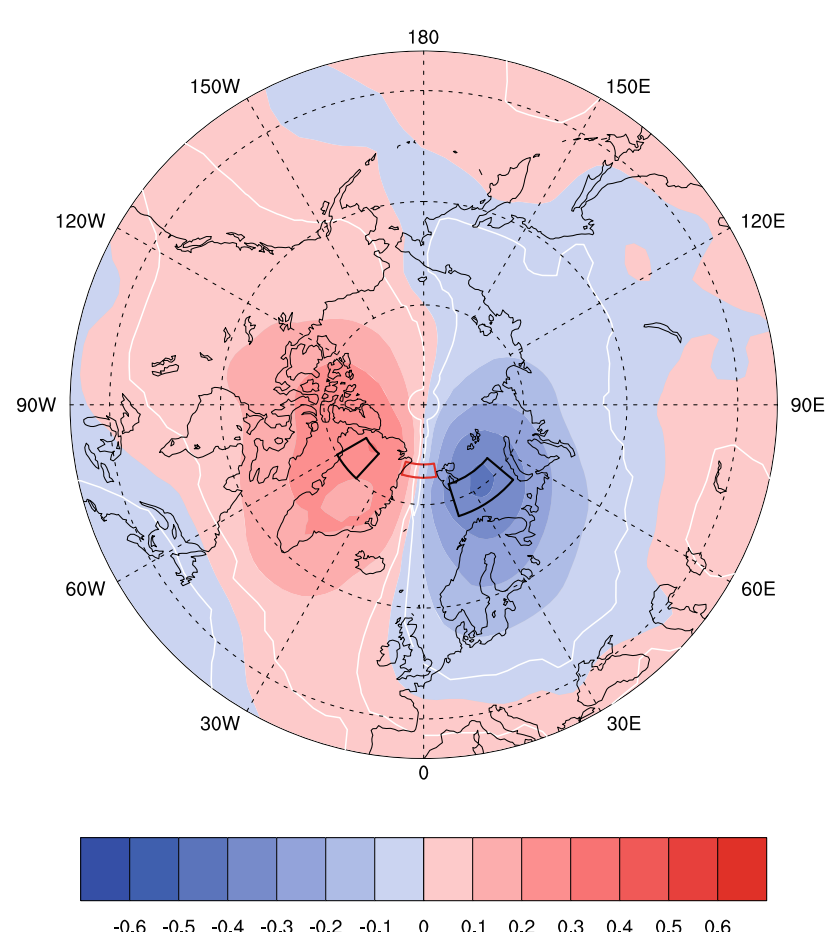

Fig. 1 Simultaneous correlation map between daily SLP anomalies and daily sea ice motion through Fram Strait during 1979-2006. White contours indicate the $99 \%$ significance levels. Fram Strait is outlined by the open red box. Black square boxes show the areas used in SLP gradient index calculation

summer during 1979-2006 separately and then average individual power spectra together.

\section{Results}

\subsection{Daily data}

Figure 1 depicts the correlation coefficient map between SLP north of $40^{\circ} \mathrm{N}$ and the Fram Strait sea ice motion index based on 10,227 days of data during 1979-2006. Due to the large sample size, correlation coefficients exceeding $\sim 0.05$ in absolute value are statistically significant at the 99\% level (outlined by white contour in Fig. 1). There are two main centers of action associated with the anomalous sea ice motion: one over Barents Sea and another one over northern Greenland and Canadian Archipelago. As the sign of the correlation coefficients suggest, southward Fram Strait sea ice motion is maximized with a Barents Sea Low and a Greenland High. Such an east-west dipole pattern is associated with geostrophic northerly winds in Fram Strait and therefore is physically consistent with increased sea ice transport. As previous studies have indicated, sea ice in the Arctic Ocean moves nearly parallel to the geostrophic wind (Thorndike and Colony 1982; Kimura and Wakatsuchi 2000).
An analogous SLP pattern has been described in the literature related to the cold-air outbreaks in Scandinavia (Kolstad et al. 2008). A similar east-west dipole pattern emerges as the second empirical orthogonal function (EOF) of the daily SLP anomalies over the Atlantic sector $\left(90^{\circ} \mathrm{W}-90^{\circ} \mathrm{E}, 45^{\circ}-90^{\circ} \mathrm{N}\right)$ during $1979-2006$ and explains $14 \%$ of the variance; while the leading EOF resembles the North Atlantic Oscillation (NAO; Hurrell 1995) and accounts for $32 \%$ of the variance (Fig. 2). Nearly identical EOF patterns and percent variances explained are obtained for the earlier period 1958-1977 (not shown), confirming the robustness of the results. Previous studies have also obtained a dipole pattern from EOF analysis based on monthly SLP anomalies (e.g., "Barents Oscillation" described by Skeie 2000, Tremblay 2001; winter dipole pattern described by $\mathrm{Wu}$ et al. 2006).

We employ the two centers of action revealed by the correlation coefficient map (Fig. 1) to construct a SLP gradient index (SLPGI). For simplicity we define the centers as rectangular boxes, both outlined in Fig. 1. The Barents center of action stretches from $72.5^{\circ}$ to $77.5^{\circ} \mathrm{N}$ and from $17.5^{\circ}$ to $50.0^{\circ} \mathrm{E}$, and the Greenland center of action occupies the area from $75.0^{\circ}$ to $80.0^{\circ} \mathrm{N}$ and from $60.0^{\circ}$ to $42.5^{\circ} \mathrm{W}$. We define the SLPGI as the difference between the two. Our results are not sensitive to the exact definition of the Barents and Greenland centers of action-bigger and smaller boxes defining the SLPGI provide similar results (not shown). It is interesting to note that the two centers of action are not significantly correlated with one another (correlation coefficient is 0.1 based on daily SLP anomalies during 1979-2006). However, when the variability associated with the leading EOF is removed from the data, the two centers of action become significantly anti-correlated (correlation coefficient is -0.4, significant at the $99 \%$ level). We interpret this as competing influences on the two centers of action, with EOF1 contributing to an in-phase relationship and EOF2 to an out-of-phase connection (e.g., dipole).

The standardized time series of the SLPGI and Fram Strait sea ice motion index for one particular winter season (1985-1986) are presented in Fig. 3. The winter of 19851986 is chosen for illustration only as it is fairly representative of the entire record. The SLPGI and ice motion index exhibit similar behavior, with an overall correlation coefficient of 0.54 , significant at the $99 \%$ level. Both time series experience substantial high frequency (sub-monthly) variability and therefore monthly averages cannot sufficiently describe these variables. Peaks and troughs of the SLPGI and ice motion time series often occur simultaneously, with no systematic lead or lag between the two. There are, however, short periods of non-simultaneous change (for example the second half of November 1985), which is expected from noisy high resolution indices. 


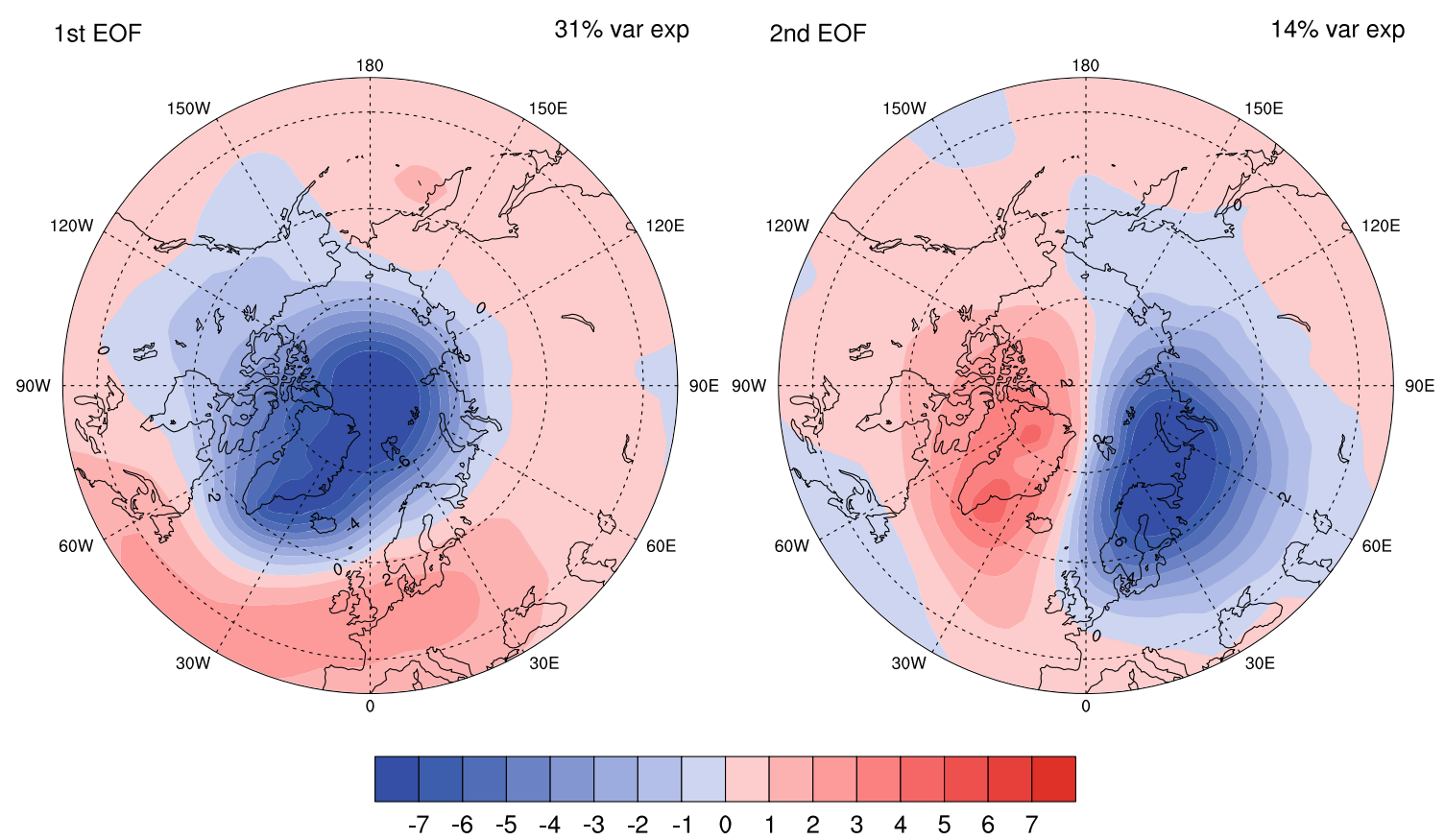

Fig. 2 First and second $\mathrm{EOF}(\mathrm{s})$ of Atlantic sector $\left(45-90^{\circ} \mathrm{N}, 90^{\circ} \mathrm{W}-90^{\circ} \mathrm{E}\right)$ daily SLP anomalies during $1979-2006$. The patterns north of $40^{\circ} \mathrm{N}$ are obtained by regressing the daily SLP anomalies at all grid point upon the PC time series

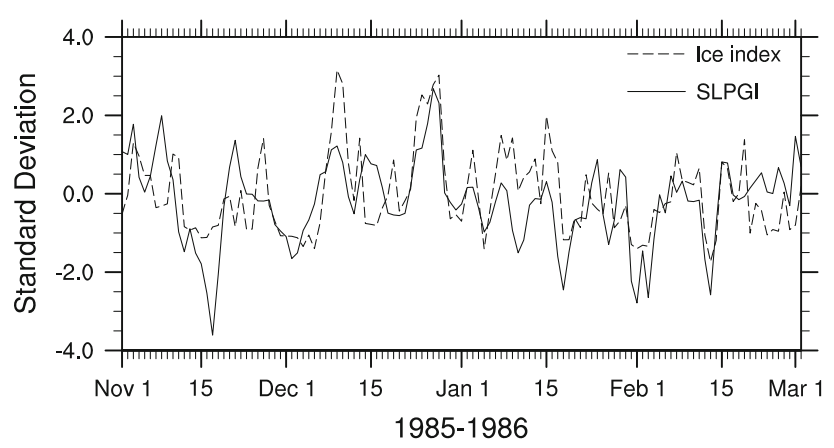

Fig. 3 Time series of the standardized daily sea ice motion index through Fram Strait (dashed) and the SLPGI (solid) during the 19851986 winter season. The correlation coefficient between the two indices is 0.54

Figure 4 depicts the anomalous SLP pattern associated with enhanced southward sea ice motion through Fram Strait, obtained by regressing the daily SLP anomaly time series at each grid point upon the daily ice motion anomaly time series. The top panel shows results based on all 10,227 days in the 1979-2006 record; the middle and lower panels depict results based on the winter (15 October-14 April) and summer (15 April-14 October) seasons of the year. The SLP regression coefficients are in the units of hPa per $\mathrm{cm} \mathrm{s}^{-1}$ and are thus representative of a $1 \mathrm{~cm} \mathrm{~s}^{-1}$ increase in the southward ice motion through Fram Strait. Overall, the seasonal variations are quite small: both the Greenland and Barents centers of action persist year-round, although they are $\sim 15 \%$ stronger (and the Barents center is also more extensive) in winter compared to summer. Thus, the same ice motion anomaly is associated with a stronger geostrophic northerly wind anomaly in winter than summer. Considering that the ice volume flux in winter is greater and more variable than that in summer (e.g., Kwok 2009), these differences are not surprising.

Due to the persistence of the east-west dipole pattern year-round, we define the SLPGI for winters and summers based on the same two centers of action (see Fig. 1). The lead/lag correlation and regression coefficients between Fram Strait sea ice motion index and the SLPGI for all days of the year, and for winter and summer separately are presented in Fig. 5. The maxima of both the correlation and regression curves occur at zero lag, and decline sharply with lag, reaching their e-folding values (0.37) at \pm 3 days (20\% of their maximum values at \pm 5 days). Such a sharp decline suggests a lack of inertia in the wind-sea ice relationship, consistent with previous results (Gudkovich 1961; Campbell 1965; Thorndike and Colony 1982). Winter values exhibit slightly greater inertia than summer as evidenced by the small correlation values at lags of \pm 8 to 15 days. Consistent with the results shown in Figs. 1 and 4, the simultaneous correlation (regression) coefficients range from 0.58 $\left(1.33 \mathrm{hPa}\right.$ per $\left.\mathrm{cm} \mathrm{s}^{-1}\right)$ in winter to $0.49(1.12 \mathrm{hPa}$ per $\mathrm{cm} \mathrm{s}^{-1}$ ) in summer. Correlation (regression) coefficients exceeding $0.05\left(0.12 \mathrm{hPa} \mathrm{cm}^{-1} \mathrm{~s}\right)$ are significant at the $99 \%$ level. The SLP gradient regression values correspond to geostrophic wind regression coefficients of $0.56 \mathrm{~cm} \mathrm{~s}^{-1}$ per $\mathrm{m} \mathrm{s}^{-1}$ in winter and $0.44 \mathrm{~cm} \mathrm{~s}^{-1}$ per m s${ }^{-1}$ in summer. The 

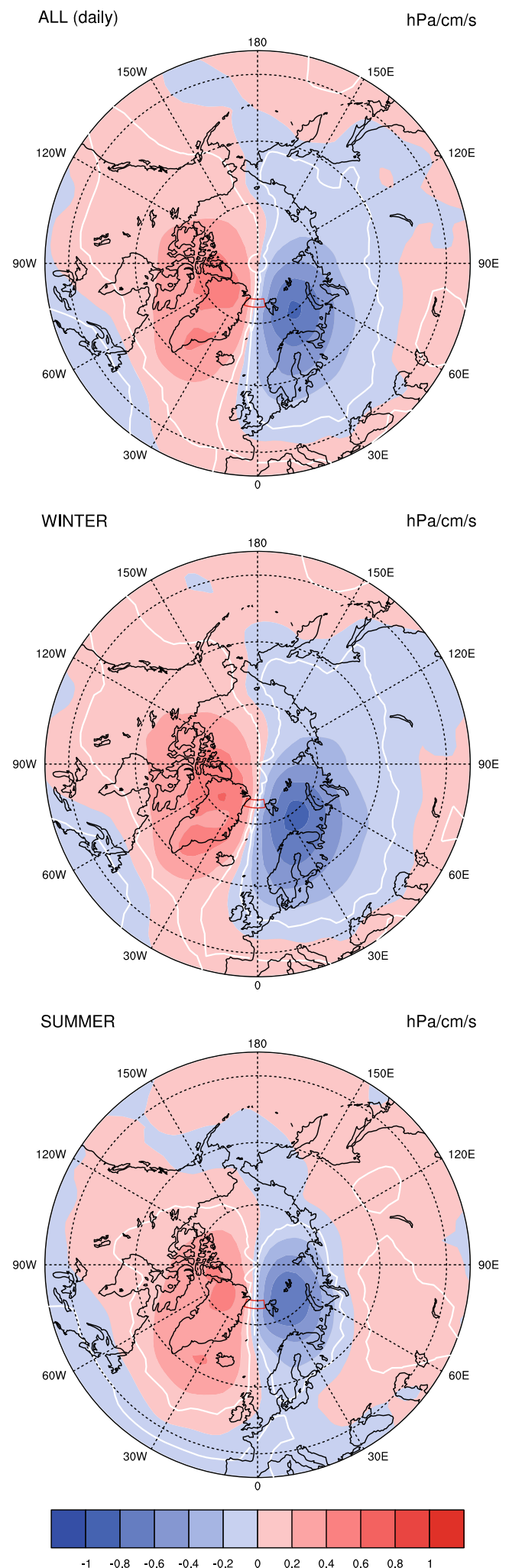

Fig. 4 Simultaneous regression of daily SLP anomalies upon daily anomalies of sea ice motion through Fram Strait based on the period 1979-2006. The top, middle and bottom panels are based on all days of the year, winters (15 October through 14 April) and summers (15 April-14 October), respectively. White contours indicate the $99 \%$ significance levels
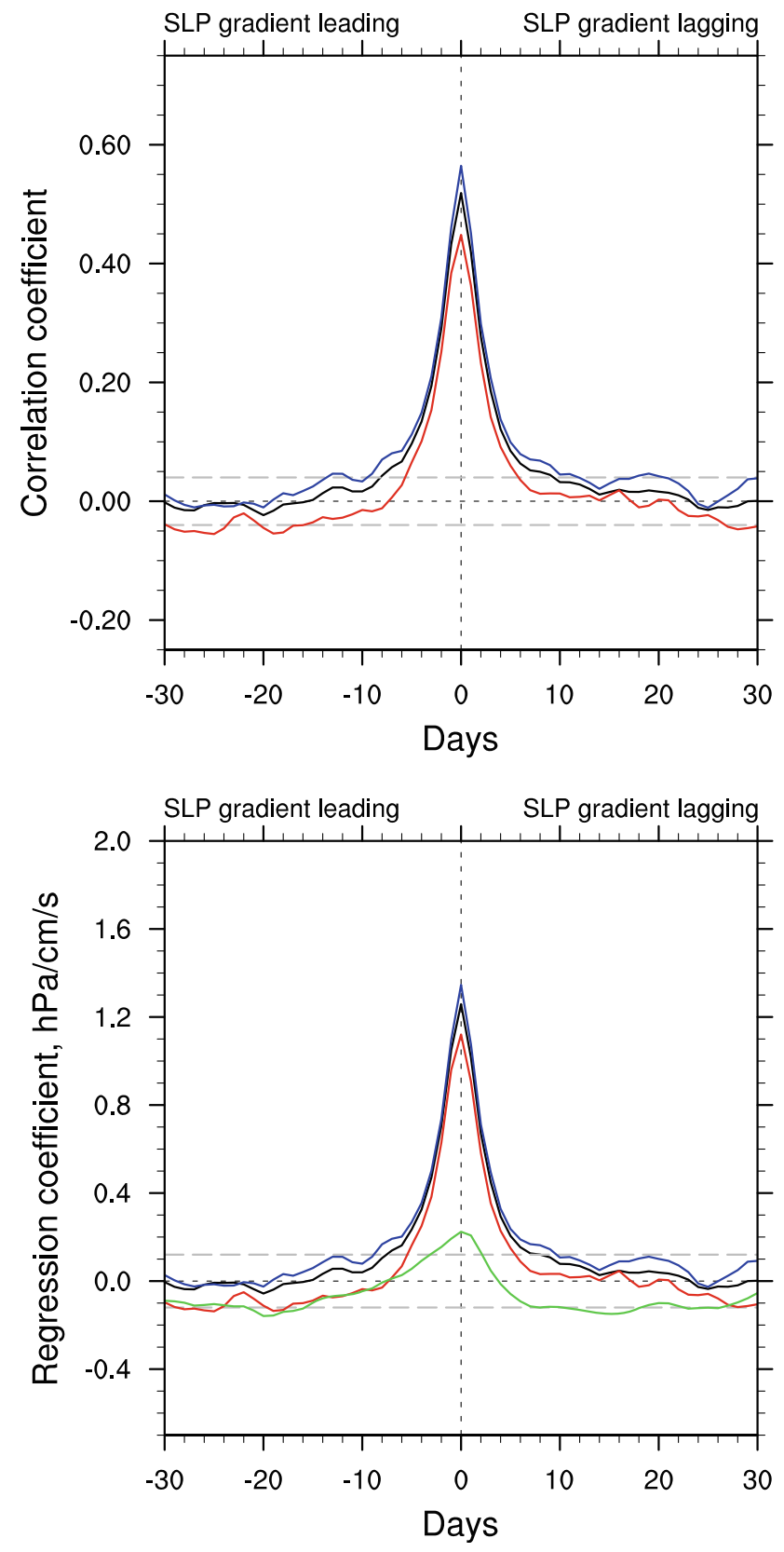

Fig. 5 Lead/lag correlation (top) and regression (bottom) coefficients between the daily SLPGI and daily Fram Strait sea ice motion during 1979-2006. Black line represents all days of the year, blue line represents winter (15 October 15 through 14 April) and red line represents summer (15 April-14 October). Dashed gray lines show the $99 \%$ significance levels. Green line in bottom panel shows the lead/lag regression between an NAO-like index (see text for details) and sea ice motion through Fram Strait in winter

simultaneous correlation coefficient between the SLPGI and ice motion index $(0.56)$ is somewhat lower than that $(0.76)$ obtained by Widell et al. (2003). Several factors may contribute to the lower correlation, including the removal of seasonal cycle in our calculation, but not in Widell et al. (2003); different time series (1979-2006 vs. 1996-2000) 
Fig. 6 Lead/lag autocorrelation coefficients between the daily SLPGI (left) and daily Fram Strait sea ice motion (right) for 1979-2006. Black line represents all days of the year, blue line represents winter (15 October through 14 April) and red line represents summer (15 April-14 October). Dashed gray lines show the $99 \%$ significance levels

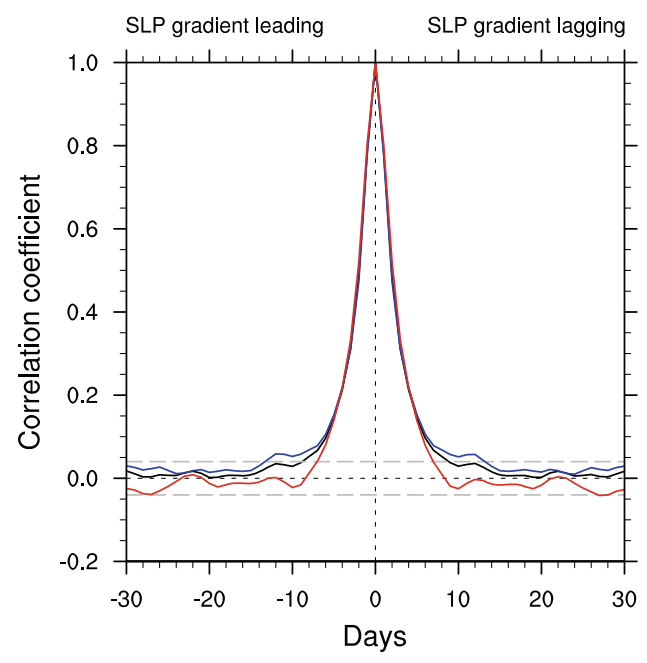

and different ice motion and SLP gradient datasets. These factors also contribute to lower geostrophic wind regression as compared to Kimura and Wakatsuchi (2000) wind reduction estimates (their Fig. 3).

It is interesting to note that the autocorrelation curves for the SLPGI and the sea ice motion index (Fig. 6) both experience a sharp decline with an e-folding time of \pm 3 days. The ice motion index, however, shows a stronger low-frequency component (e.g., memory) than the SLPGI, as evidenced by non-zero autocorrelation values at lags greater than \pm 5 days. Seasonal variations in both SLPGI and sea ice motion index are small (shown by blue and red lines in Fig. 6).

The daily data used in this study allow us to investigate the spectral character of the relationship between the SLPGI and Fram Strait sea ice motion index in detail. Figure 7 depicts the coherence between the two variables, which is equivalent to the correlation coefficient as a function of frequency. Coherence values are shown for periods between 2 days and 5 years; values exceeding 0.22 are significant at the $99 \%$ level (dashed grey line). Coherence values peak in the 10-60 day band, with values between 0.6 and 0.75 . Coherence values are lower than 0.5 at periods shorter than 5 days and longer than 200 days. Lower coherence values for periods $\gtrsim 200$ days suggest factors in addition to the localized wind forcing are important in connection with sea ice motion through Fram Strait on interannual timescales.

The seasonality of the coherence values, calculated by averaging the power spectra for each year separately, is shown in Fig. 8. Note, that this method yields higher coherence values for periods shorter than $\sim 5$ days than those in Fig. 6 due to the averaging procedure. It also can only resolve periods shorter than $\sim 180$ days. Both winters and summers exhibit maximum coherence values in the 10-60 day band, with higher coherence values in winter

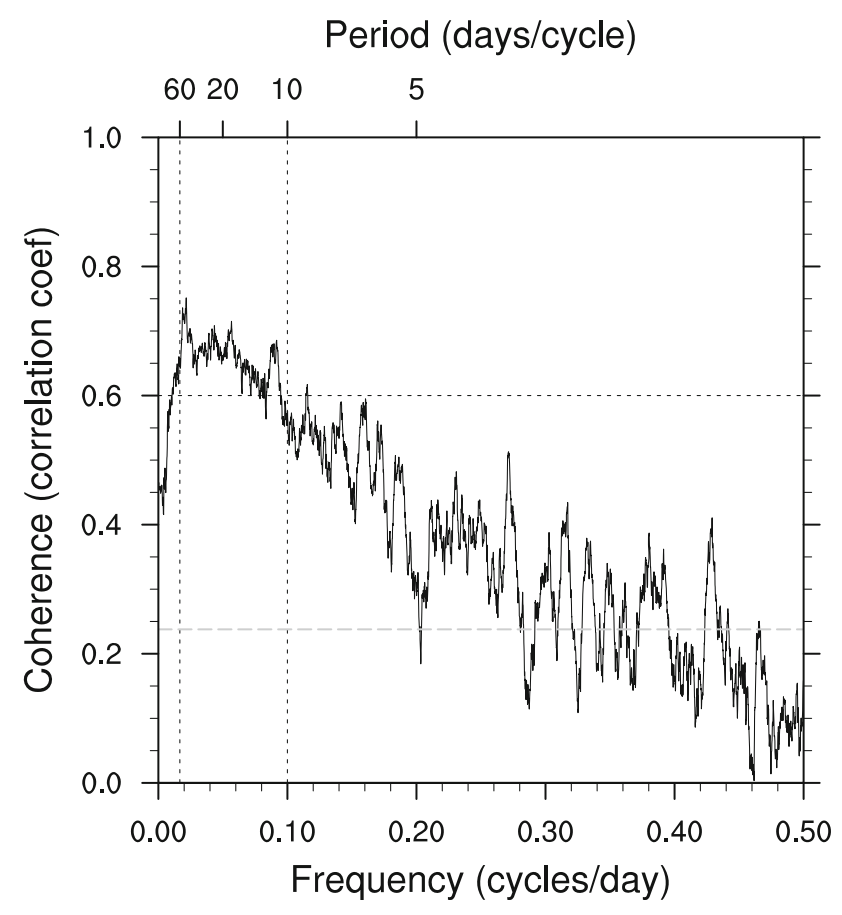

Fig. 7 Coherence between the SLPGI and Fram Strait ice motion index based on the daily anomalies during 1979-2006. Dashed gray line indicates the $99 \%$ significance value. Highest coherence values $(>0.6)$ are observed in the 10-60 day band, outlined by dotted black lines

$(0.70-0.75)$ than those in summer $(0.60-0.70)$. The winter coherence curve is very similar to that based on all days of the year, except for the higher values at periods longer than 60 days.

Given that the strongest association between the SLPGI and the Fram Strait sea ice motion index occurs in the 10-60 day range, we have recomputed the SLP regression coefficients upon the ice index using 10-60 day band pass filtered daily data. Figure 9 depicts the time evolution of 


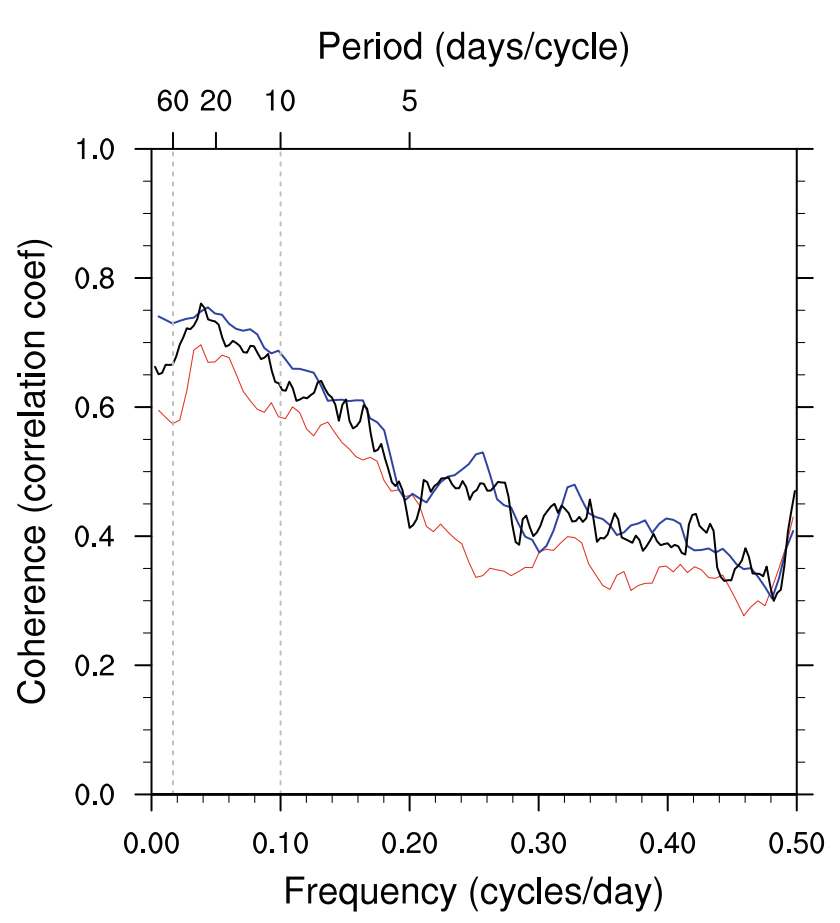

Fig. 8 Coherence values between the SLPGI and Fram Strait ice motion index, calculated by averaging the power spectra for each year separately. Black line represents all days of the year, blue line represents winter (15 October through 14 April) and red line represents summer (15 April-14 October). Note that this method yields higher coherence values for shorter periods ( $>5$ days) than that in Fig. 6. Due to discontinuity from year to year both winter and summer records extend to 180 days only, while year-round values extend to 365 days

the regression coefficients for the winter season from a lag of -8 days (SLP leading) to a lag of +8 days (SLP lagging). Similar patterns are obtained using year-round data (not shown). At -8 day lag (top left) there is a weakly defined dipole pattern of reversed sign, compared to that at 0 lag (Fig. 4 and middle panel of Fig. 9). The sign reversal is partially due to the response curve of the 10-60 day filter, while the weak amplitude of the regression values suggests a lack of inertia in the system as mentioned before. As time progresses ( -6 and -4 day lags) a low SLP anomaly moves into the Barents Sea and by -2 day lag (middle left panel) the Barents and Greenland centers are well-defined with regression coefficients values increasing dramatically. The regression coefficients reach their maximum values at $0 \mathrm{lag}$, consistent with the results based on unfiltered data. The regression pattern dissipates almost as quickly as it develops. The bottom row of panels depicts the Barents low center gradually moving southeastward at $+2,+4$ and +6 day lags. By +8 day lag (bottom right), the regression pattern once again is weak and of reversed polarity.

Figure 10 shows the lead/lag correlation and regression coefficients between the SLPGI and Fram Strait ice motion index based on the 10-60 day band pass filtered data. As expected, the simultaneous correlation regression coefficients increase after filtering (compare Figs. 5, 9), with correlation (regression) values of 0.69 $\left(\sim 2 \mathrm{hPa} \mathrm{cm}^{-1} \mathrm{~s}\right)$ in winter and $0.64\left(1.9 \mathrm{hPa} \mathrm{cm}^{-1} \mathrm{~s}\right)$ in summer. Both regression and coefficient values experience sharp declines beyond weekly lags. Negative values observed at periods of 1-3 weeks are likely to be an artifact of the filtering.

Because the Greenland center of action encompasses the region near Iceland (see Fig. 9, middle row, -2 days to +2 days lags) and because the regression values near the Azores $\left(40^{\circ} \mathrm{N}, 30^{\circ} \mathrm{W}\right)$ are of opposite polarity, a statistical relationship exists between the NAO-index and the sea ice motion through Fram Strait. To examine this association in more detail, we develop an NAO-like index based on the difference between the Icelandic $\left(55^{\circ}-65^{\circ} \mathrm{N}\right.$ and $\left.40^{\circ}-10^{\circ} \mathrm{W}\right)$ and Azores centers of actions $\left(35^{\circ}-45^{\circ} \mathrm{N}\right.$ and $\left.40^{\circ}-20^{\circ} \mathrm{W}\right)$. Note that our sign convention is opposite to the traditional definition of the NAO (Hurrell 1995). The lag regression between the NAO-like index and the sea ice motion index based on unfiltered and 10-60 day filtered data for winter only are depicted by green curves in Figs. 5 and 10, respectively. As evident from these figures, the NAO-like relationship with sea ice motion is much weaker than that of the SLPGI, although significant at the $99 \%$ level.

\subsection{Monthly data}

We repeat the correlation/regression analysis using monthly averages for direct comparison to previous studies. Figure 11 (top panel) shows the simultaneous regression of monthly SLP anomalies on the monthly sea ice motion index based on all months of the year during 19792006. The striking feature of the monthly regression map compared to the daily regression map (Fig. 4) is the disappearance of the Greenland center of action and therefore the dipole structure of the pattern. The Barents center of action is still present and statistically significant at the $99 \%$ level. Although the dipole atmospheric pattern is not present, the Barents low pressure center still produces a SLP gradient across Fram Strait, providing the necessary forcing for the underlying sea ice.

The seasonal structure of the monthly regression map is also noticeably different from that of the daily regression map. With monthly data, the Barents center of action is active in winter only, while no significant relationship between SLP and sea ice motion exists in summer. The latter result is consistent with previous studies that found that summer sea ice export is not correlated with the monthly averaged atmospheric wind forcing (e.g., Kwok et al. 2004; Wu et al. 2006; Wu and Johnson 2007). 


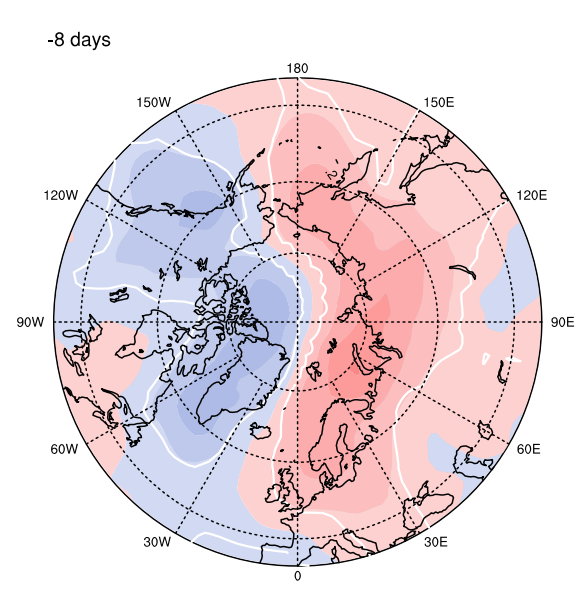

-2 days

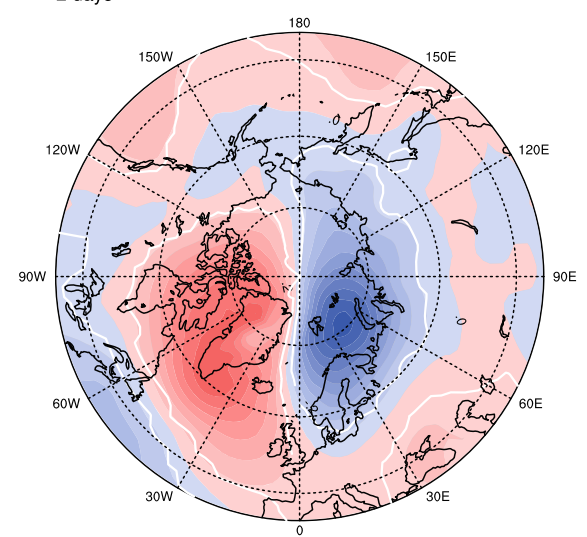

4 days

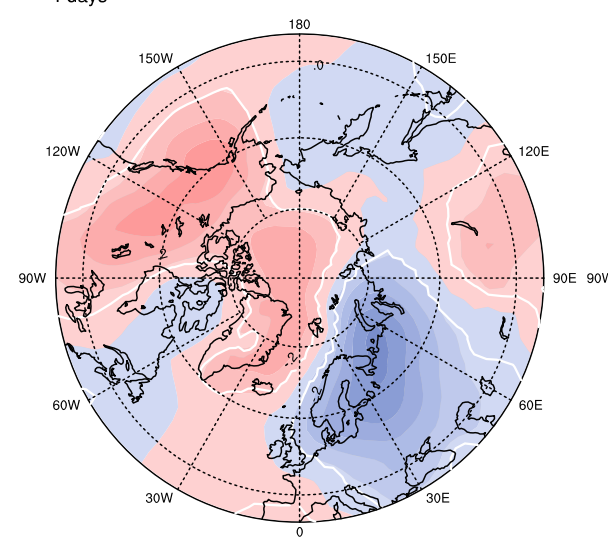

6 days

0 days
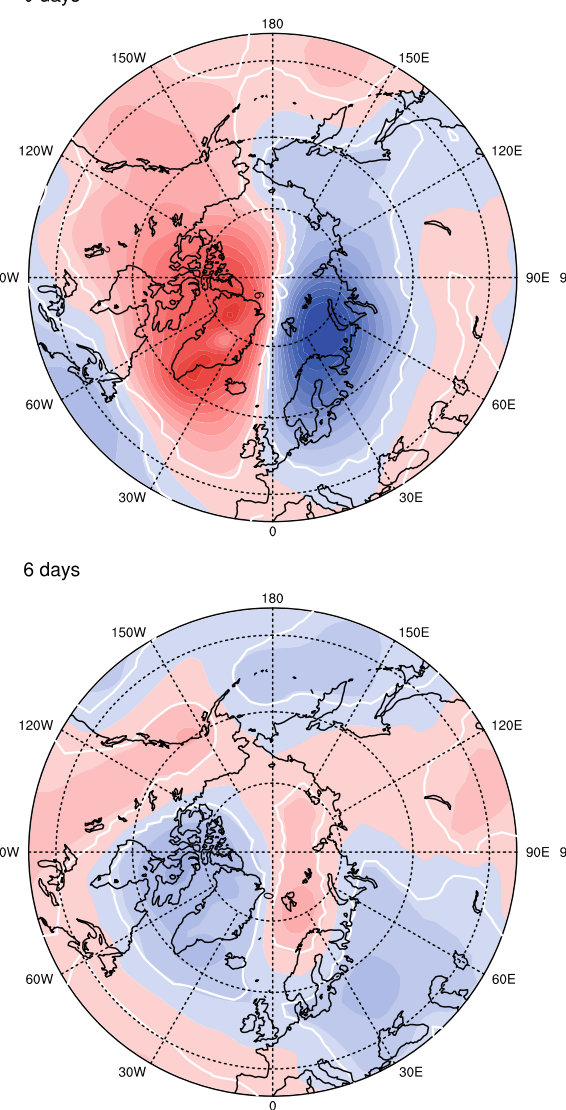

8 days

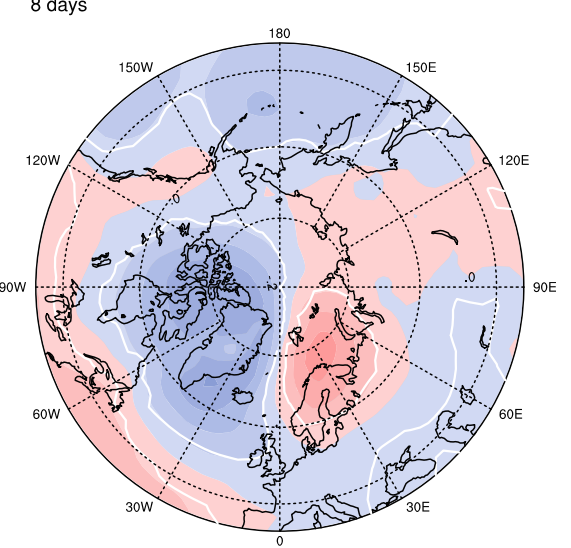

2 days

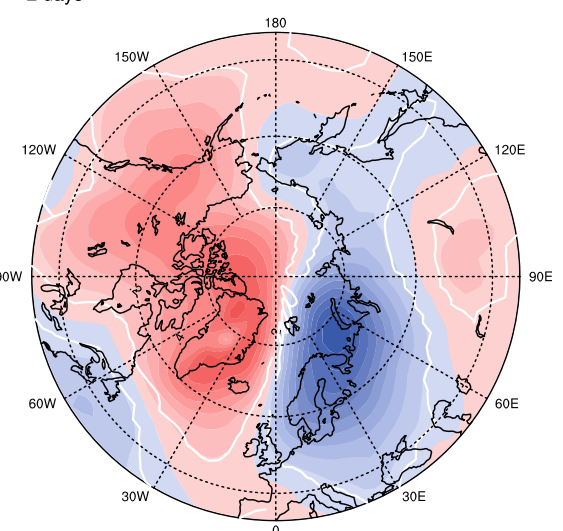

-4 days

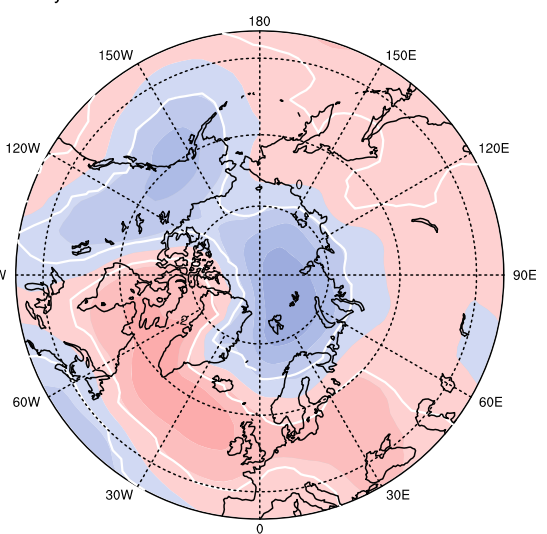

days 

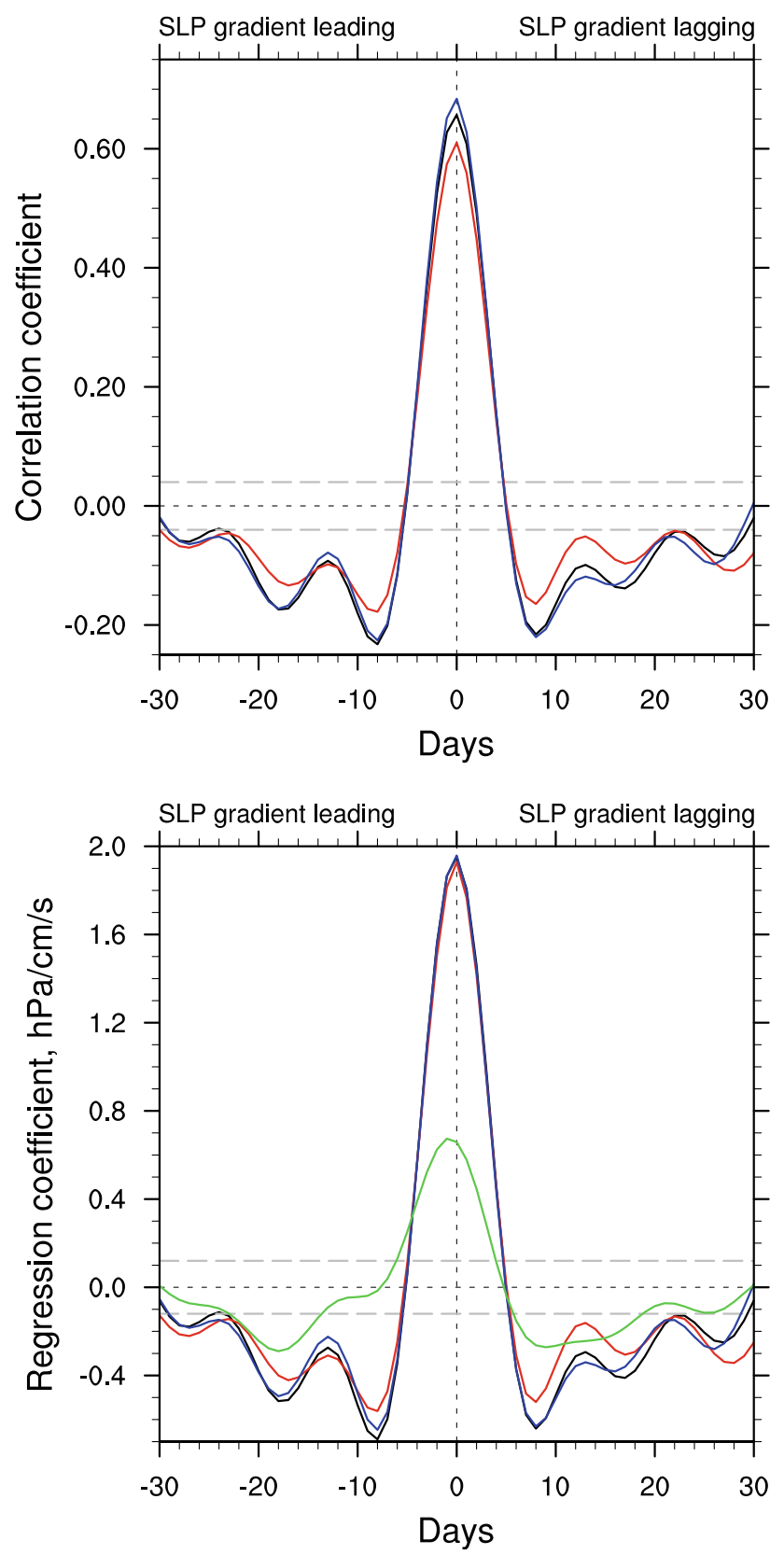

Fig. $10 \mathrm{Lead} / \mathrm{lag}$ correlation (top) and regression (bottom) coefficients between the daily SLPGI and daily Fram Strait sea ice motion based on 10-60 day band-pass filtered data for 1979-2006. Black line represents all days of the year, blue line represents winter (15 October through 14 April) and red line represents summer (15 April-14 October). Dashed gray lines show the $99 \%$ significance levels. Green line in bottom panel shows the lead/lag regression between an NAOlike index (see text for details) and sea ice motion through Fram Strait in winter

both winter and summer, and is also similar to the leading EOF of daily SLP anomalies (Fig. 2a). With the removal of the leading EOF, the monthly regression map based on year-round data (Fig. 13, top panel) is very similar to the daily regression map (Fig. 4), with both the Barents and
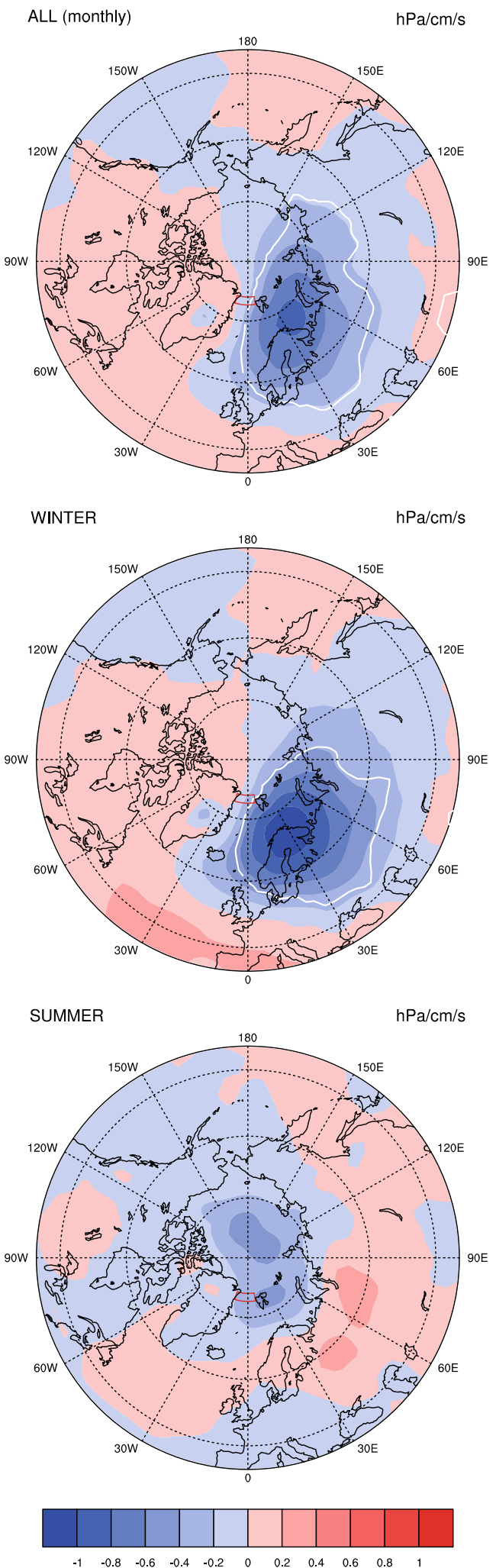

Fig. 11 Simultaneous regression of monthly SLP anomalies upon monthly anomalies of sea ice motion through Fram Strait based on the period of 1979-2006. The top, middle and bottom panels are based on all months of the year, winters (October through March) and summers (April through September), respectively. White contours indicate the $99 \%$ significance levels 

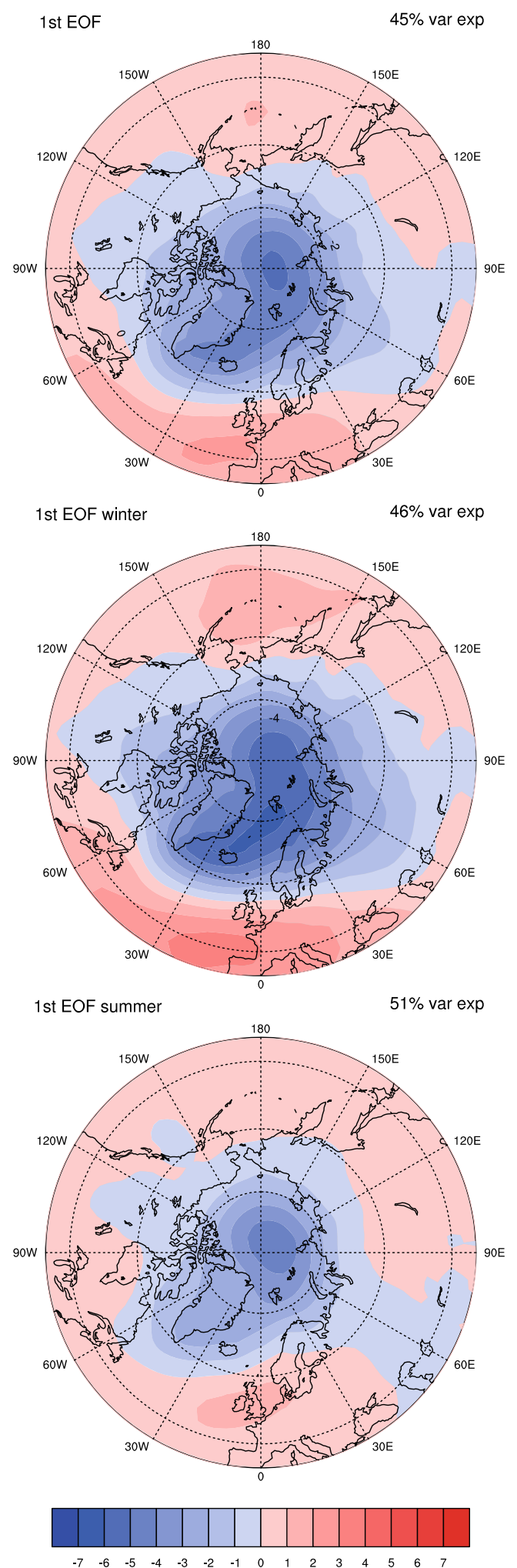

Fig. 12 The leading EOF of Atlantic sector $\left(45-90^{\circ} \mathrm{N}, 90^{\circ} \mathrm{W}-90^{\circ} \mathrm{E}\right)$ monthly SLP anomalies during 1979-2006. The top, middle and bottom panels are based on all months of the year, winters (October through March) and summers (April through September), respectively. The patterns north of $40^{\circ} \mathrm{N}$ are obtained by regressing the daily SLP anomalies at all grid point upon the PC time series

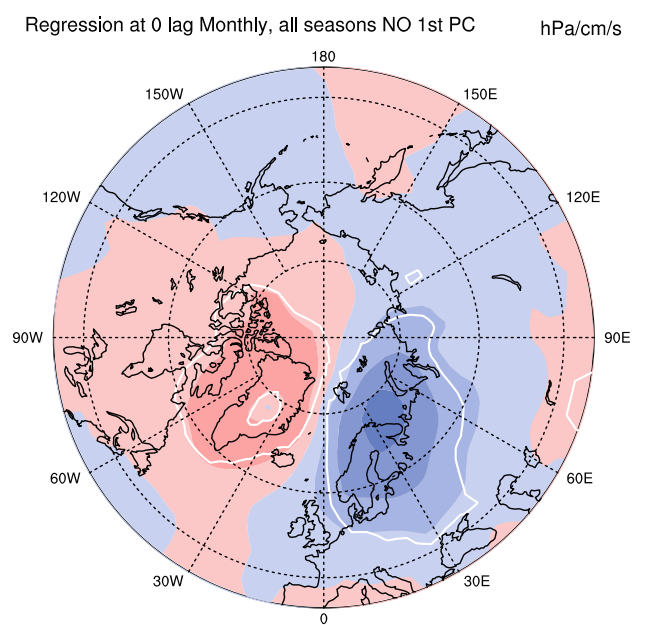

Regression at 0 lag WINTER NO 1st PC

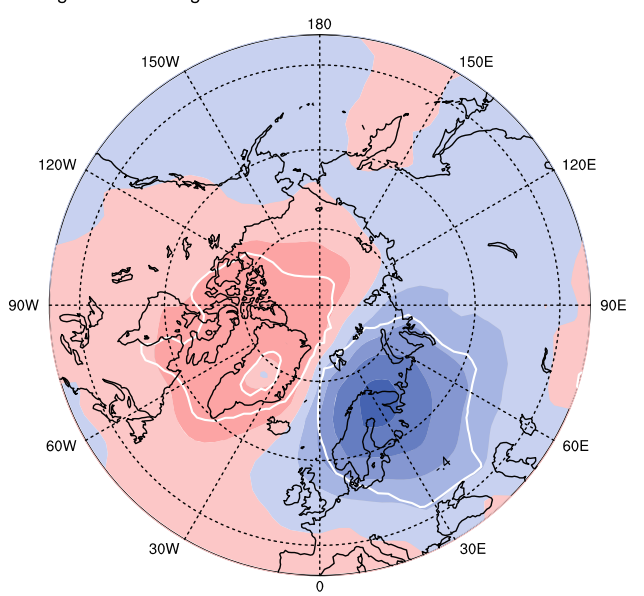

Regression at 0 lag SUMMER NO 1st PC
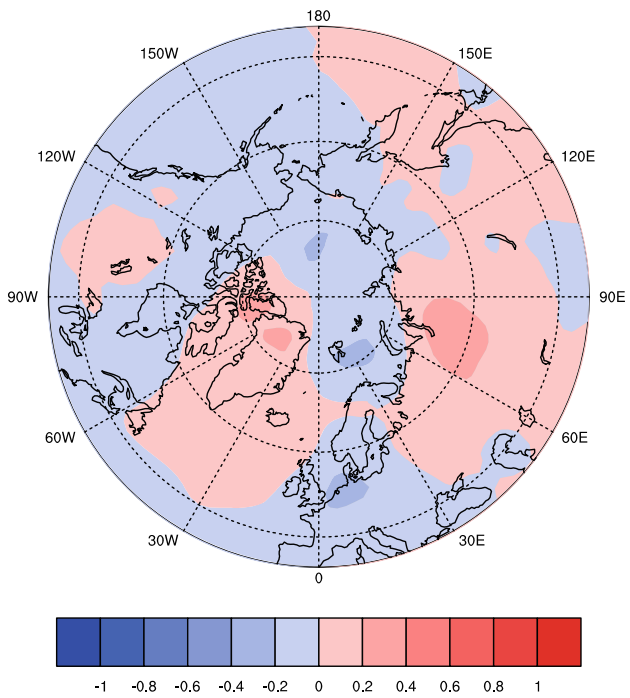

Fig. 13 As in Fig. 10, but the leading EOF of monthly SLP anomalies is removed from the data before the SLP regressions are computed. The top, middle and bottom panels are based on all months of the year, winters (October through March) and summers (April through September), respectively. The leading EOFs for year-round, winter and summer seasons are computed separately. White contours indicate the $99 \%$ significance levels 
Greenland centers of action present. The amplitude of the SLP dipole is slightly weaker than that based on daily data, but it is still significant at the $99 \%$ level.

Similar results are found for winter (Fig. 13, middle panel), with both centers of the east-west SLP dipole significant at the $99 \%$ level. However, the Barents center of action in winter is noticeably weaker when the leading EOF is removed than when it is included (compare Figs. 11, 13, middle panels). This can be partially attributed to the fact that the Barents region is included in the polar center of action of the leading EOF in winter (Fig. 12, middle panel) and thus contributes to the SLP gradient across Fram Strait. In summer (Fig. 13, bottom panel) there is no significant relationship between monthly EOF-residual SLP and Fram Strait sea ice motion. The leading EOF in summer is shifted northward compared to that in winter (Fig. 12, bottom panel). The lack of relationship between monthly SLP anomalies and Fram Strait sea ice motion in summer (Figs. 11, 13, bottom panels) suggests that high-frequency (e.g., sub-monthly) atmospheric variability plays a dominant role in forcing sea ice motion in summer (Fig. 4, bottom panel).

\section{Summary}

With the help of daily data for SLP and sea ice motion, we found that an east-west dipole pattern with Barents and Greenland centers of action is the most prominent atmospheric driver of sea ice through Fram Strait. The dipole pattern persists year-round, being slightly stronger in winter than in summer. The strongest relationship between the SLP dipole pattern and Fram Strait sea ice motion is simultaneous, with an e-folding time of $\sim 5$ days. Spectral analysis shows maximum coherence values in the 1060 day band. Such a time scale suggests that both high- and low-frequency atmospheric patterns are essential in driving sea ice out of the Arctic.

Atmospheric circulation variability on the 10-60 day time scale has been described in previous studies in association with blocking events in high latitudes (e.g., Michelangeli and Vautard 1998) and westward propagating planetary-scale perturbations (Doblas-Reyes et al. 2001) also known as Branstator-Kushnir oscillations (Branstator 1987; Kushnir 1987). The possible link between these atmospheric phenomena and the Barents-Greenland SLP dipole pattern identified in this study merits further investigation. However, we find no evidence of westward propagation of the SLP dipole (not shown). While the eastwest dipole projects onto the zonal wave 1 structure of atmospheric variability identified in Cavalieri (2002) at high latitudes $\left(70^{\circ}-80^{\circ} \mathrm{N}\right)$, it is primarily an Atlantic sector pattern farther south $\left(45^{\circ}-70^{\circ} \mathrm{N}\right)$,
Repeating our analysis using monthly data revealed a modified spatial pattern of SLP anomalies associated with Fram Strait sea ice motion. While the Barents center of action remains prominent, the Greenland center of action and therefore the dipole structure of the pattern disappeared. However, removing the leading EOF from the monthly averaged SLP data (e.g., the NAO) resulted in the return of the east-west dipole pattern. Based on these results, we argue that in monthly data the NAO-the leading intrinsic pattern of atmosphere variability-partially masks the relationship between the SLP dipole pattern and the Fram Strait sea ice motion response. That is, the NAO is not the most dynamically relevant pattern for explaining the variations in sea ice motion through Fram Strait. Rather, the east-west SLP dipole pattern is the important driver of the anomalous sea ice motion both in daily and monthly averaged data. These results help explain why previous studies based on monthly data (e.g., Hilmer and Jung 2000; Vinje 2001; Kwok et al. 2004) found no consistent relationship between the NAO and Fram Strait sea ice motion.

This study investigated the role of atmospheric forcing in driving Fram Strait sea ice motion. It will be interesting to extend this study to examine the relationship between atmospheric forcing and Fram Strait sea ice volume flux by incorporating observational estimates of sea ice thickness. Ice volume changes in the Arctic sea ice are crucial for determining the future behavior of sea ice extent and important for linking the thermodynamic and dynamic components of sea ice change (Holland et al. 2008). As Rigor and Wallace (2004) have argued, the loss of sea ice extent in recent years was preconditioned by the loss of older and thicker sea ice through Fram Strait in the 1990s. We plan to investigate the processes that triggered the sea ice loss of the 1990s in greater detail,

Acknowledgments We thank the reviewers for their insightful comments and suggestions that substantially improved the manuscript. We also thank Christophe Cassou for helpful suggestions, and Adam Philips and Dennis Shea for technical assistance in preparation of the figures. This work was supported by a grant from the National Science Foundation Arctic System Science Program. The National Center of Atmospheric Research is sponsored by the National Science Foundation.

\section{References}

Bloomfield P (1976) Fourier analysis of time series: an introduction. Wiley, New York, pp 151-181

Branstator G (1987) A striking example of the atmosphere's leading travelling pattern. J Atmos Sci 44:2310-2323

Brummer B, Muller G, Affeld B, Gerdes R, Karcher M, Kauker F (2001) Cyclones over Fram Strait: impact on sea ice and variability. Polar Res 20(2):147-152 
Brummer B, Muller G, Hoeber H (2003) A Fram Strait cyclone: properties and impact on ice drift as measured by aircraft and buoys. J Geophys Res 108:4217-4230. doi:101029/2002 JD002638

Campbell WJ (1965) The wind-driven circulation of ice and water in a Polar Ocean. J Geophys Res 70(14):3279-3301

Cavalieri DJ (2002) A link between Fram Strait sea ice export and atmospheric planetary wave phase. Geophys Res Lett 29(12):1614. doi:101039/2002GL014684

Dickson RR, Meincke J, Malmberg SA, Lee AJ (1988) The "Great Salinity Anomaly" in the northern North Atlantic, 1968-1982. Prog Oceanogr 20:103-151

Doblas-Reyes FJ, Pastor MA, Casado MJ, Deque M (2001) Wintertime westward-traveling planetary scale perturbations over the Euro-Atlantic region. Clim Dyn 17:811-824

Duchon C (1979) Lanczos filtering in one and two dimensions. J Appl Meteorol 18:1016-1022

Fowler C (2003) Polar pathfinder daily $25 \mathrm{~km}$ EASE-grid sea ice motion vectors. National Snow and Ice Data Center. Digital media, Boulder

Gudkovich ZM (1961) Relation of the ice drift in the Arctic Basin to ice conditions in Soviet Arctic seas (in Russian). Trudy Okeanographicheskoi Komissii 11:14-21

Hilmer M, Jung T (2000) Evidence for a recent change in the link between the North Atlantic Oscillation and Arctic sea ice export. Geophys Res Lett 27:989-992

Holland MM, Serreze MC, Stroeve J (2008) The sea ice mass budget of the Arctic and its future change as simulated by coupled climate models. Clim Dyn. doi:10.1007/s00382-008-0493-4

Hurrell JW (1995) Decadal trends in the North Atlantic Oscillation: regional temperatures and precipitation. Science 269:676-679

Julian PR (1975) Comments on the determination of significance levels of the coherence statistic. J Atmos Sci 32:836-837

Jung T, Hilmer M (2001) The link between the North Atlantic Oscillation and Arctic sea ice export through Fram Strait. J Clim 14:3932-3943

Kalnay E, Kanamitsu M, Kistler R, Collins W, Deaven D, Gandin L, Iredell M, Saha S, White G, Woolen J, Zhu Y, Chelliah M, Ebisuzaki W, Higgens W, Janowiak J, Mo KC, Ropelewski C, Wang J, Leetma A, Reynolds R, Jenne R, Joseph D (1996) The NCEP/NCAR 40-year reanalysis project. Bull Am Meteorol Soc 77:437-471

Kimura N, Wakatsuchi M (2000) Relationship between sea-ice motion and geostrophic wind in the Northern Hemisphere. Geophys Res Lett 27(22):3735-3738

Koenigk T, Mikolajewicz U, Haak H, Jungclaus J (2006) Variability of Fram Strait sea ice export: causes, impacts and feedbacks in a coupled climate model. Clim Dyn 26:17-34. doi:10.1007/ s00832-005-0060-1

Kolstad E, Bracegirdle TJ, Seierstad IA (2008) Marine cold-air outbreaks in the North Atlantic: temporal distribution and associations with large-scale atmospheric circulation. Clim Dyn. doi: 10.1007/s00382-008-0431-5

Kushnir Y (1987) Retrograding wintertime low-frequency disturbances over the North Pacific Ocean. J Atmos Sci 44:2727-2742

Kwok R (2009) Outflow of Arctic Ocean sea ice into the Greenland and Barents Seas: 1979-2007. J Clim 22:2438-2457

Kwok R, Rothrock DA (1999) Variability of Fram Strait ice flux and North Atlantic Oscillation. J Geophys Res 104(C3):5177-5189

Kwok R, Cunningham GF, Pang SS (2004) Fram Strait sea ice outflow. J Geophys Res 109(C1):Art. No. C01009

Maslanik J, Drobot S, Fowler C, Emery W, Barry R (2007) On the Arctic climate paradox and the continuing role of atmospheric circulation in affecting sea ice conditions. Geophys Res Lett 34:L03711. doi:10.1029/2006GL028269

Michelangeli P-A, Vautard R (1998) The dynamics of Euro-Atlantic blocking onset. Q J R Meteorol Soc 124:1045-1070

Press WH, Flannery BP, Teukolsky SA, Vetterling WT (1986) Numerical recipes. The art of scientific computing. Cambridge University Press, London, pp 484-488

Rigor IG, Wallace JM (2004) Variations in the Age of Arctic sea-ice and summer sea-ice extent. Geophys Res Lett 31:L09401. doi: 10.1029/2004GL019492

Rigor IG, Wallace JM, Colony RL (2002) Response of sea ice to the Arctic Oscillation. J Clim 15:2648-2663

Rogers JC, Yang L, Li L (2005) The role of Fram Strait winter cyclones on sea ice flux and on Spitsbergen air temperatures, Geophys Res Lett 32(6):Art. No. L06709

Skeie P (2000) Meridional flow variability over the Nordic seas in the Arctic Oscillation framework. Geophys Res Lett 87:5845-5852

Thompson DW, Wallace JM (1998) The Arctic Oscillation signature in the wintertime geopotential height and temperature fields. Geophys Res Lett 25:1297-1300

Thorndike AS, Colony R (1982) Sea ice motion in response to geostrophic winds. J Geophys Res 87:5845-5852

Tremblay B (2001) Can we consider the Arctic Oscillation independently from the Barents Oscillation? Geophys Res Lett 28:42274230

Tsukernik M (2007) Characteristics of the winter cyclone activity in the northern North Atlantic and its impact on the Arctic freshwater budget. PhD Thesis, University of Colorado, 153

Vinje T (2001) Fram Strait ice fluxes and atmospheric circulation: 1950-2000. J Clim 14:3508-3517

Widell K, Osterhus S, Gamelsrod T (2003) Sea ice velocity in the Fram Strait monitored by moored instruments. Geophys Res Lett 30(19):1982. doi:101029/2003GL018119

Wu B, Johnson MA (2007) A seesaw structure in SLP anomalies between the Beaufort Sea and the Barents Sea. Geophys Res Lett 31. doi: 101029/2006GL028333

Wu B, Wang J, Walsh J (2006) Dipole anomaly in the winter Arctic atmosphere and its association with sea ice motion. J Clim 19:210-225 